\title{
Termalismo Social no Sistema Único de Saúde: ampliando ações e olhares quanto ao uso terapêutico da água
}

\section{Social Thermalis in the Brazilian National Health System: broadening actions and perspectives on the therapeutic use of water}

$\mathrm{A}$ utilização da água como elemento terapêutico recebe diferentes denominações. Essas nomenclaturas variam segundo o tipo da água, temperatura, composição química, formas de utilização e até mesmo segundo as profissões que fazem uso do recurso. Podemos encontrar denominações tais como balneoterapia, crenoterapia, talassoterapia, crioterapia, hidroterapia, hidroginástica, hidrologia médica, entre outras, além do termo “Termalismo Social”, conforme expresso na Política Nacional de Práticas Integrativas e Complementares ${ }^{1}$ (PNPIC). Sem pretendermos esgotar as discussões a respeito das diferenças nas terminologias quanto ao uso das águas nos cuidados à saúde, tampouco sobre as disputas e tensões homéricas nos campos profissionais, é importante esclarecer, brevemente, algumas dessas diferenças conceituais.

"Balneoterapia" é o termo amplamente utilizado internacionalmente. Refere-se ao conjunto de práticas terapêuticas realizadas por meio de banhos quentes ou mornos com águas mineiras naturais, geralmente praticados na fonte - portanto nos balneários ${ }^{2,3}$. "Balneologia" (Balneology) representa o estudo da balneoterapia, e é o descritor utilizado nas publicações científicas internacionais ${ }^{3}$, muitas vezes como sinônimo de "termalismo" “Crenoterapia” é o uso de águas minerais no cuidado à saúde, normalmente por indicação de ingesta, sendo uma prática complementar a ser associada a outros tratamentos, estando esta assegurada na PNPIC ${ }^{1}$. Já a "talassoterapia” compreende o tratamento pela água do mar e elementos marinhos, tais como algas e sais. A "Crioterapia” versa sobre a aplicação terapêutica de diferentes técnicas com água em baixas temperaturas em diferentes regiões do corpo, utilizada comumente na reabilitação fisioterápica e em procedimentos estéticos.
Por sua vez, o termo "hidroterapia" é bastante polissêmico e às vezes controverso. Usado historicamente desde o século XIX pelos naturopatas - especialmente por conta do legado do padre alemão Sebastian Knei$\mathrm{pp}^{4}$-, ao menos no Brasil, atualmente é sinónimo de técnicas fisioterápicas e confundido pela população leiga como hidroginástica. Mas em Naturopatia ${ }^{4}$ e Naturologia, a hidroterapia consiste em distintas formas de aplicação da água nas diferentes temperaturas (não necessariamente termomineral na fonte), tais como compressas, pachos, jatos de água direcionados, banhos alternados e em geral. Em Fisioterapia, hidroterapia (ou ainda fisioterapia aquática/hidrocinesioterapia) abrange técnicas e exercícios aquáticos personalizados, utilizados em procedimentos de reabilitação $0^{5}$. Já a hidroginástica seriam atividades físicas praticadas na água, conduzidas por profissionais da Educação Física $^{5}$. E hidrologia médica seria o tratamento com o uso das águas no âmbito da Medicina.

Por sua vez, "termalismo" refere-se ao uso de águas termominerais naturais na recuperação, manutenção e ampliação da saúde; como visto, pode ser utilizado como sinônimo de Balneoterapia. Quando qualificado enquanto Termalismo Social, tal como expresso na PNPIC ${ }^{1}$, o sentido de termalismo é ampliado. Cabe ressaltar que o termo não é um neologismo criado no âmbito do SUS. Já na década de 1950, "termalismo social" era usado para indicar o "[...] sistema pelo qual o tratamento termal, uma vez dificilmente acessível a qualquer um além dos ricos, foi disponibilizado, em condições altamente satisfa-

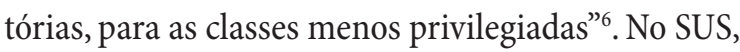
o termo não é expresso em relação do Termalismo a uma política de Estado residual, senão como direito de acesso universal. Além da noção de saúde como 
direito, termalismo social, no SUS, vai além das abordagens individuais e coletivas de cuidado, que utiliza as águas termominerais como elemento terapêutico, abarcando a complexidade da prática dentro da ótica da promoção da saúde, alinhada aos princípios do SUS. Destarte, a promoção da saúde em termos do Termalismo Social vai além do aspecto técnico da aplicação terapêutica da água e seus benefícios orgânicos para manter e recuperar a saúde; ela abrange ainda a complexidade que envolve a saúde e sua determinação social, demandando assim abordagem intersetorial e interdisciplinar. Desse modo, o Termalismo Social, para além dos benefícios biológicos provenientes do uso terapêutico das águas termominerais, é problematizado ainda em suas dimensões ecológica, social, cultural, política, econômica, lúdica, subjetiva e psicológica.

O Termalismo Social se configura como prática promotora de saúde, sobretudo quando pensada em termos de proteção ambiental, geração de emprego e renda, turismo e lazer, e resgate de saberes e práticas populares em saúde. Mais do que uma prática terapêutica, o Termalismo Social é um modelo de atenção à saúde sistêmico e complexo, multiprofissional, pautado nos princípios da universalidade, integralidade e equidade, e condizente com os eixos fundamentais da perspectiva clínica ampliada e compartilhada ${ }^{7}$.

Como visto, o termalismo social e a crenoterapia são reconhecidos no SUS enquanto práticas integrativas e complementares, sendo, portanto, garantido o direito de acesso aos usuários. Todavia, tais práticas se encontram no SUS como observatórios, certamente devido a seu pouco uso, seja pela pouca formação de profissionais especializados para atuarem na área ou pela inexistência atual de modelos de financiamento próprio no SUS para essas práticas, além de outros motivos. Embora o Brasil possua muitas cidades com potencial balneário para o termalismo em saúde, ainda são poucos os locais inscritos no Cadastro Nacional de Estabelecimentos de Saúde: apenas 12 cadastros em outubro de 2014 ${ }^{1}$, nenhum em Santa Catarina, estado que conta com, pelo menos, 14 municípios com estâncias termais ${ }^{2}$, o que revela a real situação do termalismo social na saúde pública brasileira.

Com o intuito de fortalecer o termalismo social no âmbito do SUS, a Secretaria de Estado da Saúde de Santa Catarina, por meio de sua Diretoria de Educação Permanente em Saúde (DEPS/SES-SC) e da Escola de Saúde Pública de Santa Catarina, em parceria com o curso de Naturologia, da Universidade do Sul de Santa Catarina (UNISUL), criaram o projeto "Termalismo Social na Atenção Básica Catarinense: Realidade, Sensibilização e Ação". Esse projeto tem como objetivo fomentar ações e serviços de Termalismo Social, bem como sensibilizar os gestores e os profissionais da área da saúde para a Política Nacional de Práticas Integrativas e Complementares na atenção básica no Estado de Santa Catarina, visando ampliar o acesso. $\mathrm{O}$ referido projeto possui recursos aprovados pelo Ministério da Saúde, convênio $\mathrm{n}^{\circ}$ 795180/2013, publicado no Diário Oficial da União em 09/01/2014. Dentre os objetivos específicos do projeto, consta a produção de conhecimento científico e material informativo concernente ao termalismo social-Crenoterapia, tal como se configura esta edição especial da revista Cadernos de Naturologia e Terapias Complementares.

Nesta edição, encontram-se artigos e comunicações, resumos de tese e dissertação que abordam aspectos históricos do termalismo no Brasil e no mundo, aspectos ecológicos da exploração das águas minerais, características da balneoterapia na França, Alemanha, Polônia, e Brasil (Caldas da Imperatriz $\mathrm{SC}$ ), assim como os mecanismos de ação da balneoterapia. A revista finaliza com uma entrevista especial com Carmen de Simoni e Tiago Pires de Campos, os quais estiveram à frente da Política Nacional de Práticas Integrativas e Complementares, marcando a história recente e o presente do termalismo social na saúde pública e coletiva no Brasil.

Espera-se que esta edição da Cadernos de Naturologia e Terapias Complementares seja um disposi-

1 Para localizar os estabelecimentos de saúde cadastrados, basta acessar o site http://www.cnes.datasus.gov.br, ir em relatórios, serviços especializados, localizar "Serviço de Práticas Integrativas e Complementares" e, após, selecionar a classificação "Termalismo Crenoterapia”.

2 (1) Santo Amaro da Imperatriz; (2) Águas Mornas; (3) Gravatal; (4) Tubarão; (5) Santa Rosa de Lima; (6) Itá; (7) Treze Tílias; (8) Piratuba; (9) Caibi; (10) Águas de Chapecó; (11) São Carlos; (12) Palmitos; (13) Quilombo; (14) São João do Oeste. 
tivo para o fortalecimento do termalismo social no SUS. Portanto, faz-se jus agradecimentos especiais aos autores que enviaram seus trabalhos; aos avaliadores da revista; à Universidade do Sul de Santa Catarina, curso de Naturologia; à Secretaria de Estado da Saúde de Santa Catarina, especialmente à Divisão de Educação Permanente e Escola de Saúde Pública - notadamente os servidores Andréia Costa Tostes, Fernando de Toledo Barros Wendhausen, Maria de Fátima de Souza Rovaris; ao Ministério da Saúde do
Brasil - Departamento de Atenção Básica, especificamente à servidora Roberta Marins de Sá; à Sociedade Francesa de Hidrologia e Climatologia Médica, sobretudo à Dra. Pascale Jeambrun; e ao editor chefe desta revista, Prof. Daniel Maurício de Oliveira Rodrigues. Gratidão.

\section{Fernando Hellmann}

Organizador

\section{REFERÊNCIAS}

1. Brasil. Ministério da Saúde. Secretaria de Atenção à Saúde. Departamento de Atenção Básica. Política Nacional de Práticas Integrativas e Complementares no SUS - PNPIC SUS. Brasília: Ministério da Saúde, 2006.

2. Quintela MM. Saberes e práticas termais: uma perspectiva comparada em Portugal (Termas de S. Pedro do Sul) e no Brasil (Caldas da Imperatriz). Hist Cien Sau 1:239-260, 2004.

3. Balneology. MeSH Terms. Disponível em: http://www.ncbi.nlm.nih. gov/mesh/?term=Balneotherapy Acesso em 25 de outubro de 2014.

4. Kneipp S. Metodo de hidroterapia. [S.1.]: Editorial Maxtor. España (ed.), 1898. ISBN 84-95636-49-2.

5. Conselho Federal de Educação Física. As diferenças entre Hidroginástica e Hidroterapia. Revista E.F. No. 20 - Julho de 2006. Disponível em: http://www.confef.org.br/extra/revistaef/show. asp?id=3620 Acesso em 25 de outubro de 2014.

6. Lemaire J. "SOCIAL THERMALISM" IN BELGIUM. Annals of Public and Cooperative Economics, 27: 1-13, 1956. doi: 10.1111/j.14678292.1956.tb01226.x

7. Brasil. Ministério da Saúde. Secretaria de Atenção à Saúde. Política Nacional de Humanização da Atenção e Gestão do SUS. Clínica ampliada e compartilhada / Ministério da Saúde, Secretaria de Atenção à Saúde, Política Nacional de Humanização da Atenção e Gestão do SUS. - Brasília : Ministério da Saúde, 2009. 